\title{
Web-Based Scaffolding Teaching of EAP Reading and Writing
}

\author{
Wanyi Du, Chunyue Zhou \\ Foreign Language Education Centre, Kaifaqu Campus of Dalian University of Technology, Dalian, China \\ Email: wendydudu@msn.com
}

How to cite this paper: $\mathrm{Du}, \mathrm{W}$. Y., \& Zhou, C. Y. (2019). Web-Based Scaffolding Teaching of EAP Reading and Writing. Creative Education, 10, 1863-1872.

https://doi.org/10.4236/ce.2019.108134

Received: July 15, 2019

Accepted: August 11, 2019

Published: August 14, 2019

Copyright (C 2019 by author(s) and Scientific Research Publishing Inc. This work is licensed under the Creative Commons Attribution International License (CC BY 4.0).

http://creativecommons.org/licenses/by/4.0/

\section{(c) (i) Open Access}

\begin{abstract}
With the deepening development of educational reform of College English, its transformation has become an inevitable problem. EAP teaching has become a new topic in College English teaching under the objective situation of the great progress where bilingual teaching in key national universities has made. Based on the Sydney School's scaffolding instruction framework of EAP reading and writing, in combination of the training objectives and course settings for the talents from advanced science and engineering universities, we have conducted an empirical research on web-based scaffolding pedagogy of EAP literacy cultivation. In the follow-up questionnaires, students have general reflex that independent EAP reading and writing ability has met a significant improvement, and the awareness of self-learning and cooperative learning has been fully tapped.
\end{abstract}

\section{Keywords}

Web-Based, Scaffolding, EAP Reading and Writing

\section{Introduction}

The Outline of the National Medium- and Long-Term Program for Education Reform and Development has been implemented in July, 2010. As China's education reform outline for the next decade and China's first educational plan after entering the 21st century, this Outline is a programmatic document to guide the reform and development of national education in the coming period. It has been claimed again in the outline that training high-end talents in basic disciplines with first-class international level and promoting the level of basic scientific research in China is one of the objectives of cultivating national higher pedagogy personnel. The students from key national universities are the main force of China's future scientific research team, therefore their academic reading and writing 
abilities will undoubtedly represent the international communication ability of China's future scientific research team. In recent years, with the deepening of the reform of bilingual teaching, College English teaching in key colleges and universities has tended to pave the foundation for bilingual courses of different majors, and to promote students to quickly and smoothly adapt to the bilingual courses of their own major. "Tsinghua University has made a great adjustment to the curriculum of College English which has resolutely cut out Comprehensive English, the national-level high-quality curriculum of and, instead, opened a series of EAP courses, which bringing another spring for College English" (Cai, 2012). Under the new situation, how to carry out EAP teaching actively and effectively has become an inevitable problem in the teaching of College English.

\section{Scaffolding Pedagogy of EAP Reading and Writing}

The pedagogy of Sydney School is considered as one of the three genre-based teaching approaches. Some scholars also believe that Sydney School and ESP School are two representative schools of Genre-based Teaching Approach from the perspective of linguistics (Flowerdew, 2002). This pedagogy is influenced by the theory of "scaffolding instruction" of Lev Vygotsky, a famous psychologist in the former Soviet Union. Vygotsky believes that there may be differences between the problems needed to be solved and the original abilities in children's intellectual activities, that is, the "Zone of Prozimal Development". Scaffolding Instruction refers to giving full play to the potential development ability of the students in the "Zone of Prozimal Development", and stimulates students' enthusiasm to study actively through the scaffolds established by teachers. The scaffolds will provide help to students when they need it, and will be removed when their abilities grow, finally, the goal of students' autonomous learning and lifelong learning will be realized.

Scaffolding pedagogy of academic reading and writing aims at effectively improving interdisciplinary literacy with the core of scaffolding-based interactive circulating which guides students to complete academic reading and writing tasks through the interactions between teachers and students. Scaffolding pedagogy of academic literacy includes four circulating steps: preparation for reading, independent reading, preparation for writing and independent writing. Among them, preparing for reading and writing is the most important step and teachers' roles of scaffolding will be embodied here, which is the focus of the whole teaching process. Teachers will customize various forms of scaffoldings for different student in advance, and help them complete the preset tasks through teacher-student interaction in the classroom according to certain teaching steps. After a period of training, it will finally realize extracurricular reading and writing independently, as well as the independent use and output of language.

\section{Teaching Practice of Web-Based Scaffolding Academic Reading and Writing}

In order to ensure that the senior students can successfully complete bilingual 
learning of their own majors, the author's university offers a fundamental course, English for Software Industry, for sophomore students which lasts for 16 teaching weeks, 2 hours per week, and the teachers are from College English Department. Compared with other English courses, this course has longer teaching cycle, longer intervals between two teaching periods, and are more academic, the demands for teachers' academic literacy is higher. Both teachers and students should make full use of their free periods and prepare for learning in advance so as to effectively improve classroom efficiency. Therefore, after in-depth discussion about curriculum, design, implementation and evaluation, we finally chose the wed-based scaffolding pedagogy of academic reading and writing to as the teaching practice of this course. Based on the theoretical framework of Sydney School's scaffolding instruction of English academic literacy, in combination of the training objectives and course settings for the talents from advanced science and engineering universities, we have sorted out the web-based scaffolding teaching mode of EAP academic reading and writing ability for those talents (Figure $1)$.

\subsection{Establishing "The Teaching Scaffold" on Network Platform}

Teachers must fully understand that the essence of scaffolding pedagogy is that teachers should do a good job of cushioning to guide students to complete tasks quickly and accurately, rather than "testing" students with problems and tasks (Rose, 2007, quoted from Chen, 2010). This is the essential difference between scaffolding pedagogy and any previous teaching mode. We use the developed medium online, QQ, an instant communication tool of Tencent Company, to register a virtual learning zone for each class. The learning zone realizes the functions of instant communications between teachers and students, file sharing, voice conference and video conference, and creates a 24-hour English learning environment for students. In addition, we have also actively developed rich network teaching resources, such as network resources and media materials and have set up an information center in the learning zone in the aspects of background information, field introduction, terminology interpretation, content structure, in

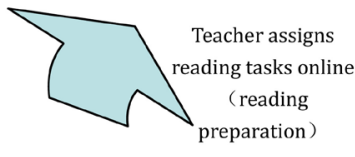

$$
\begin{gathered}
\text { Teacher and students } \\
\text { evaluation in class } \\
\text { after writing }
\end{gathered}
$$

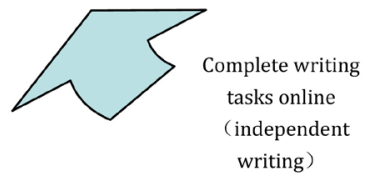

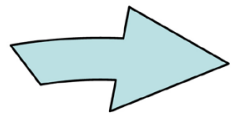

reading tasks (independent reading )

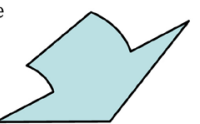

Discussion between teacher and students in class after reading
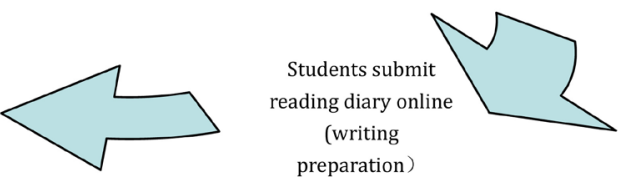

Figure 1. The teaching process of web-based scaffolding EAP reading and writing. 
order to build an overall framework for students to improve their academic literacy.

\subsection{Teaching Practice on Network Platform}

\subsubsection{Preparing for Reading: Teacher Assigns Reading Tasks Online}

Teacher will assign reading tasks through the file sharing function in the online learning zone. The professionalism of EAP requires teachers to provide introduction and reading guidance for students so that they can complete their reading tasks. Due to the limitation of teaching environment, the traditional pre-class preparation of academic reading and writing class cannot be fully utilized. Most students will only read the text extensively in advance to complete the pre-class task which the teachers usually assign students to read after class. Because of the lack of teachers' guidance, the reading efficiency is low and the effect is unsatisfactory. But on the network platform, teachers are able to give full play to the function of "scaffolding", providing students with online reference materials, instant reading guidance, the latest relevant information and so on. According to the main characteristics of this course, we mainly give "scaffold" about problems and guidance for students. Teachers will suggest the difficulties and design problems students may encounter in reading, and provide relevant network links to help them complete reading tasks.

\subsubsection{Independent Reading: Students Complete the Reading Tasks both Online and in the Textbook}

In order to improve the teaching efficiency, more and more attention has been paid to pre-class reading. Before a dialogue between teachers and students happens, students must complete the tasks preset by teachers and mark the difficulties and their puzzles, which is not only the academic basis for effective teacher-student dialogue teaching, but also the key to cultivate students' autonomous learning ability. Students can ask their classmates and instructors for consultation and discussion at any time in the online virtual learning zone once they encounter difficulties in understanding during the reading process. The problems will be solved immediately and the students can get emotional support and confidence, so that can continue to complete the reading task on their own initiative, which is difficult to achieve in a traditional classroom. Scaffolding pedagogy emphasizes the key role of "collaborative learning" in meaning construction, and collaboration should be spread in the whole teaching activities of reading. During the independent reading process, students can also spontaneously hold an audio conference, video conference and discussion activities in online learning zone, moreover, a learning community can be set up by only several students, then they can make exchanges, so that can improve their learning consciousness, and promote the cultivation of their autonomous learning ability.

\subsubsection{Discussion after Reading: Interactions between Teacher and Students and Deepening Discussion in the Class}

After pre-class discussion in the online virtue learning zone, academic reading 
teaching can reach a deeper level in the classroom teaching process, without wasting any time on the easy vocabulary, sentences and content understanding of paragraphs. Teachers lead students to complete text comprehension quickly through teaching guidance in comprehensive forms of listening, speaking, reading and writing. For example, teachers lead students to mark topic information, terminology interpretation, background analysis, and teach students independent reading ability imperceptibly. In reading and writing class, classroom discussion replaces the traditional teacher's lengthy lecture. In class situational discussion, teachers play the role of organizer and commentator, and the learning mode will transform from being indoctrinated by teacher to learning through group discussion. Students will study cooperatively, learn from others' experience, rethink the process of self-learning, so that can improve their understanding and construction ability. Teachers will ask students to take turns to read their notes to the whole class, while inviting other to supplement and discuss. This social learning mode can practice learners' cooperative, expressive and communicative abilities. The interaction between learners and their surroundings promotes their initiatives.

\subsubsection{Preparing for Writing: Students Submit Learning Diary Online}

We have introduced the teaching process of asking students to submit learning diaries which is a preparing task for beginning critical writing. Through writing learning diaries, students will learn to think independently and have a sense of academic writing. Learning diaries help students combine existing and new knowledge, open channels for communication between students and teachers, and help students test their learning progress, so that eventually become active learners. Learning diaries help teachers find the pedagogy focus, explore how students build their own knowledge system, and discover missing links during teaching process. Learning diaries promote teachers to become learners (Francis, 1995), and re-examines the advantages and disadvantages during teaching process from the perspective of students. Relevant studies abroad have proved that learning diaries can help students actively participate in learning activities and improve their writing ability (Kelly, 2001). The difference between submitting learning diaries online and on paper is that teachers can select representative diaries to share with the whole class every week, and stimulate students' interests in learning through the learning process among the their peers.

\subsubsection{Independent Writing: Students Complete Writing Task Independently Online}

After completing the stages of reading guidance, thinking process of independent reading, deepening discussion through interactions between teachers and students and rethinking step of learning diaries, the students begin the stage of independent writing. Through the instant sharing function of the network classroom, students' excellent articles can be shared by the whole class, thus achieve common learning. We emphasize that writing is a process of discussion, writing and revision, and we allow students to make mistakes then learn from them. The 
method of process writing has irreplaceable advantages, but it challenges the writing teaching in traditional classroom greatly due to its operation. Writing teaching is gradually integrated into network technology because these problems can be overcome on network platform. Students can freely choose writing time in accordance to their own situation. The different submitting time of students' writing tasks brings convenience in time arrange for teachers' corrections. Especially the modification function of electronic documents makes the process writing effective greatly. Of course, homework online will bring new problems, such as network plagiarism. For articles suspected of plagiarism, we use Paper Similarity Detection System of Wanfang Data to evaluate and judge the degree of plagiarism. Usually, after two to three times of plagiarism warning and punishment of rewriting, students will gradually give up the idea of plagiarism, learn to quote references correctly, and complete writing tasks independently.

\subsubsection{Evaluation after Writing: Evaluation in the Class after Writing}

Headings, or heads, are organizational devices that guide the reader through your paper. There are two types: component heads and text heads. Many scholars have found that evaluation is the main factor affecting students' learning, while teaching itself ranks second. The post-writing evaluation in this paper is a supplement to the Sydney School's Scaffolding Instruction of EAP Reading and Writing. In many areas of China, the evaluation step of English learning in senior high schools is neglected because it is test-oriented. At the beginning, students feel fresh and enthusiastic about the evaluation, but the content of the evaluation focuses more on the language itself. With the advancement of the curriculum, students will have a deeper understanding of the significance of evaluation, and have direct experience that evaluation plays a role in promoting learning. The evaluation includes the evaluation of autonomous learning ability, group collaborative learning and the meaning construction of the learned knowledge. In this study, teachers conduct evaluations by evaluation mean with a combination of subjectivity and objectivity, for example: students are asked to give the group leader and group members a score on the table of classroom performance evaluation ( 1 - 10 points) from the aspects of cooperation consciousness, group contribution, and write comments and messages on each other's learning diary. This study found that teachers' evaluation and mutual evaluation among students are more emotional support and harvest for them. Emotional satisfaction is helpful to encourage students to invest more time and energy in learning.

\section{Feedback on Teaching Effect}

\subsection{Design of the Survey and Questionnaires}

After one semester (16 teaching weeks) of teaching practice, the author conducted an anonymous survey and questionnaires on teaching effect among students. A total of 56 questionnaires were sent while 53 valid questionnaires were retrieved. The content of the questionnaire is divided into objective ques- 
tions and subjective questions. The objective section contains eight questions in two groups with details shown in Table 1. The questions are grouped into: web-based scaffolding vs traditional pedagogy on EAP literacy cultivation part and learning outcome of web-based scaffolding pedagogy part. The subjective section of is complementary to the objective section and concentrated on influencing factors.

\subsection{Results of Survey and Questionnaires}

\subsubsection{Comparison between Web-Based Scaffolding Pedagogy of} Academic Literacy and Traditional Reading and Writing Classroom 85 percent of the students think that the traditional reading and writing class attaches more importance to the teaching process, while the web-based scaffolding pedagogy of academic literacy relying attaches more importance to the learning process, and students feel being valued. Students recognize themselves as the main body of teaching, and teachers are more likely to act as instructors, supervisors and coordinators. 95 percent of the students think that the new teaching mode breaks through the traditional one, because it has higher teaching efficiency, and can better mobilize the enthusiasm of students, cultivate students' independent reading and writing ability, and lays a good foundation for students to read the original books of this major independently in the future. Details are show in Table 2.

\subsubsection{After Completing the Tasks in English Class, What Kinds of Ability Do You Feel You Have Improved?}

Students generally reflect that this teaching mode helps them to recognize their potential development space, and subtly guides them to accept and internalize independent reading and writing consciousness (Figure 2). $88 \%$ of the students

Table 1. Survey questions of web-based scaffolding pedagogy of EAP literacy cultivation.

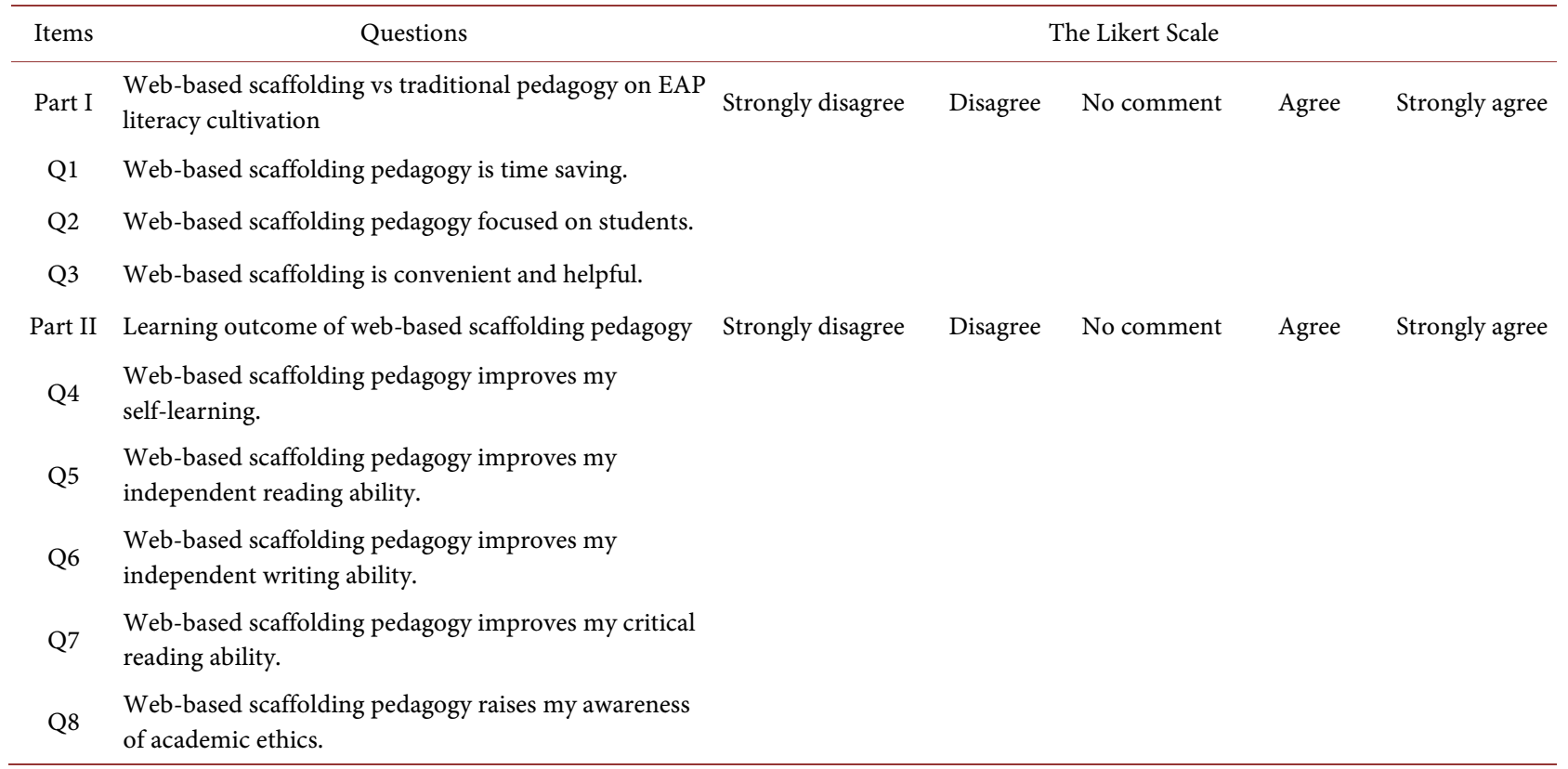


Table 2. Result of the advantages of web-based scaffolding pedagogy on EAP literacy cultivation.

\begin{tabular}{ccc}
\hline Part I & $\begin{array}{c}\text { Web-based scaffolding vs traditional } \\
\text { pedagogy on EAP literacy cultivation }\end{array}$ & Percentage of agree \\
\hline 1 & Web-based scaffolding pedagogy is time saving & $96 \%$ \\
2 & Web-based scaffolding pedagogy focused on students & $85 \%$ \\
3 & Web-based scaffolding is convenient and helpful & $95 \%$ \\
\hline
\end{tabular}

\section{Improvement on abilities}

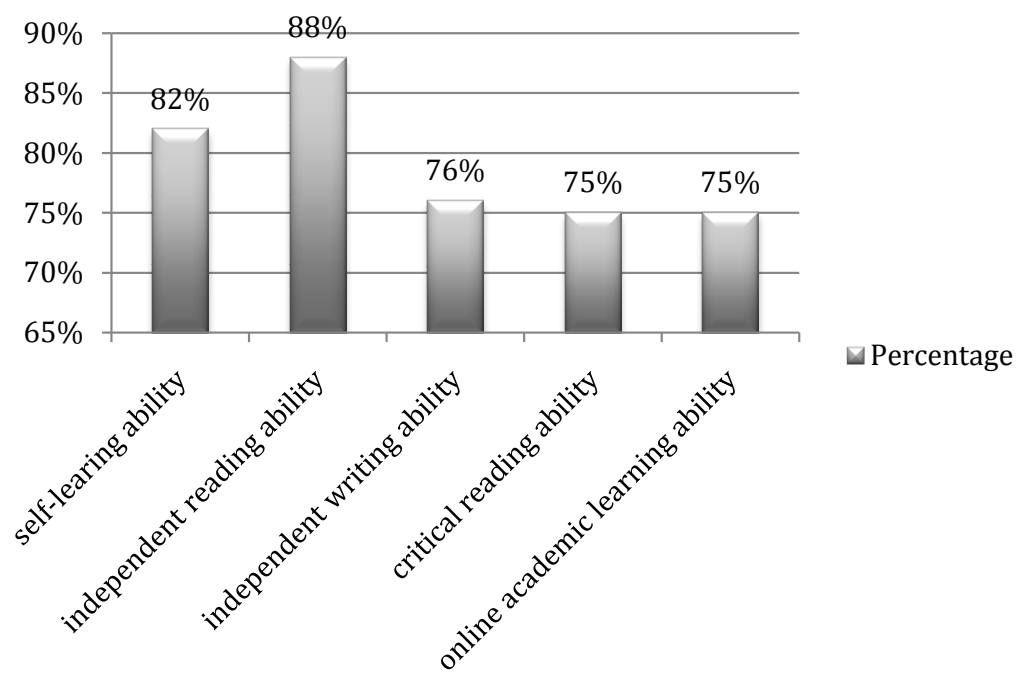

Figure 2. The concrete manifestation of the improvement of students' learning ability under this teaching mode.

think that they have improved their independent reading ability, and $82 \%$ think that they have improved their self-learning ability. At the same time, students also give positive feedback on the other three aspects of the cultivation of independent writing ability, critical reading thinking, and integrating them into academic learning ability.

\section{Conclusion}

Through the practice of scaffolding pedagogy of English academic literacy, this study explores the innovative mode of cultivating the literacy of the talents from advanced science and engineering universities. By abandoning the traditional learning methods which teacher speaks and students listen in the classroom, we are bold in adopting the latest international scaffolding pedagogy of academic reading and writing, and develop the experimental study of training academic literacy on the network platform. We make full use of the advantages of instant learning and cooperative learning of the online "virtual classroom" to stimulate students' learning initiative, and systematically train their ability of independent learning and researching. Combining with the situation of China, we firstly sort out the framework of learning mode of English literacy for the talents from ad- 
vanced science and engineering universities, enriching and supplementing the practical experience of developing teaching mode of EAP reading and writing in China. This learning mode not only emphasizes the cultivation of students' autonomous learning ability, but also pays attention to the leading and guiding position of teachers during the learning process, which is the direct embodiment of functional linguistics and constructivism teaching theory.

In addition, through this teaching practice, we are deeply aware of the decisive significance of teachers' academic literacy to teaching quality in EAP teaching. The significance of scaffold in scaffolding learning mode is teachers' pre-class preparation and the establishment of scaffold, therefore this kind of pedagogy has greatly high requirements for teachers. Teachers' preparation of scaffolding can directly influence the quality of students' learning. Teachers should have a solid knowledge of English teaching to control the classroom, and guide students to complete reading tasks through various forms of classroom activities. At the same time, it is necessary for teachers to have sufficient professional background knowledge, understand the frontier trends of this field, so as to realize the role organizer and commentator in a classroom, stimulate students' study enthusiasm, improve students' cognitive and their quality of learning. Teachers in our research group have used their holidays to have a deep internship in certain enterprise to understand human resources and training work. Teachers have been reflecting that it is overwhelming of knowledge updating and they must keep pace with the times, update their knowledge structure and enhance their academic literacy so as to calmly cope with the classroom pressure of EAP teaching. Because this study was an initial attempt to apply web-based scaffolding pedagogy to EAP literacy cultivation, more trainings are required for teachers to skillfully use various scaffolding and intervention strategies. Future studies might further examine the side effects of formative assessment and positive and negative effects of group learning in the process online discussion.

\section{Conflicts of Interest}

The authors declare no conflicts of interest regarding the publication of this paper.

\section{References}

Cai, J. (2012). General English or Academic English-A Direction We Must Choose. Journal of Northeast Normal University, 1, 94-96.

Chen, J. (2010). Applying Sydney School Genre-Based Approach to EAP Writing in China. Guangzhou: Sun Yat-Sen University Press.

Flowerdew, J. (2002). Genre in the Classroom: A Linguistic Approach. In A. M. Johns (Ed.), Genre in the Classroom: Multiple Perspective (pp. 91-102). Mahwah, NJ: Routledge.

Francis, D. (1995). The Reflective Journal: A Window to Pre-Service Teachers' Practical Knowledge. Teacher \& Teaching education, 11, 229-241.

https://doi.org/10.1016/0742-051X(94)00031-Z 
Kelly, P. (2001). First Year Engineers-Given Half a Chance... In 12th Annual Conference (pp. 1-7). Brisbane: Queensland University of Technology.

Rose, D. (2007). Reading to Learning: Accelerating Learning and Closing the Gap. Sydney: Reading to Learn. 